\title{
Donepezil for Lewy Body Constipation: A Six-Month Follow-up
}

\section{Lepkowsky $\mathrm{CM}^{*}$}

Independent Practice, 1143 Deer Trail Lane, Solvang, California 93463, USA

*Corresponding author: Dr. Charles M. Lepkowsky, Independent Practice, 1143 Deer Trail Lane, Solvang, California 93463, USA, Tel: 805-688-1229, Fax: 805-686-9382; E-mail: clepkowsky@gmail.com

Rec date: August 14, 2017; Acc date: August 29, 2017; Pub date: September 1, 2017

Copyright: (c 2017 Lepkowsky CM. This is an open-access article distributed under the terms of the creative commons attribution license, which permits unrestricted use, distribution, and reproduction in any medium, provided the original author and source are credited.

\begin{abstract}
In a previous case study, four patients at different stages of Parkinson's disease (PD) and Neurocognitive Disorder with Lewy Bodies (NCDLB) disease progression were treated with Donepezil, with the intention of mitigating Lewy body impairment of the cholinergic pathways in the myenteric plexus, increasing bowel motility, and reducing the symptom of constipation. In all four cases, the use of Donepezil was associated with significant reduction of the symptom of constipation. There was no exacerbation or instigation of other symptoms. The symptom status of the four patients was reviewed six months later. In none of the patients has there been exacerbation of the symptom of constipation, nor emergence of new symptoms. The findings suggest that Donepezil might have long-term efficacy for reducing constipation in patients with PD and NCDLB. Further research is recommended using larger numbers of subjects matched for diagnosis, age, gender, and other variables.
\end{abstract}

Keywords: Donepezil; Parkinson's disease; Neurocognitive disorder; Constipation

\section{Introduction}

In a previous case study, it was hypothesized that the use of Donepezil might mitigate the symptom of constipation [1]. Research was reviewed demonstrating that (a) constipation in Parkinson's disease (PD) and Neurocognitive Disorder with Lewy Bodies (NCDLB) is the consequence of Lewy pathology in the myenteric plexus [2-8]; (b) $95 \%$ of innervation in the myenteric plexus (which controls motility in the colon) is cholinergic [9]; (c) constipation is a frequent Lewy body symptom producing difficulties for both patients and providers of care [10,11]; and (d) for patients with neurocognitive disorders, conventional constipation treatments have proven ineffective [12].

\section{Discussion}

Because Lewy pathology impairs cholinergic function [13-17], cholinergic agonists like cholinesterase inhibitors (AChEIs) are prescribed to NCDLB and PD patients with the intention of mitigating cholinergic impairment. Data were also reviewed demonstrating that (e) among AChEIs, Donepezil has performed well [18-22]; (f) a Cochrane database systematic review found that Donepezil produced consistent reduction in neurocognitive symptoms in patients with PD and NCDLB, without exacerbation of Parkinsonian features or other side effects [23]; (g) Donepezil has reduced constipation in nongeriatric affective patients [24]; and (h) Donepezil increased cholinergically mediated bowel contractions as much as $477 \%$ in patients suffering from severe intestinal dysmotility [25].

Based on the data, four patients at different stages of PD and NCDLB disease progression were treated with $5 \mathrm{mg}$ to $10 \mathrm{mg}$ HS doses of Donepezil, with the intention of mitigating Lewy body impairment of the cholinergic pathways in the myenteric plexus, increasing bowel motility, and reducing the symptom of constipation. In all four cases, the use of Donepezil was associated with significant reduction of the symptom of constipation. There was no exacerbation or instigation of other symptoms.

The symptom status of the four patients in the previous case study was reviewed six months later. In two of the four patients, there were no symptom changes. In the other two patients, there was some exacerbation of Lewy body symptoms including blunted affect, dysphoric mood, generalized anxiety, sleep disturbance (onset, median and terminal waking, REM sleep behavior disorder or RSBD and/or REM sleep without atonia, or RSWA), cognitive interference (shortterm memory loss and difficulty with word-finding), passive suicidal ideation, appetite suppression, and exacerbation of Parkinsonian features (motor retardation, joint and muscle pain, reduced range of motion, diminished strength and coordination, increased tremor, gait disturbances, and difficulties with balance). However, in none of the four patients has there been exacerbation of the symptom of constipation, nor emergence of new symptoms.

\section{Conclusion}

These findings suggest that the use of Donepezil might have longterm efficacy in reducing constipation in patients with $\mathrm{PD}$ and NCDLB, through a mechanism that specifically mitigates Lewy body cholinergic impairment in the myenteric plexus. Further research is recommended using larger numbers of subjects matched for diagnosis, age, gender, and other variables.

\section{Informed Consent}

Written consent was provided by each of the four patients described in the case studies to release the clinical information contained therein. Patient identifiers have been kept to a minimum.

\section{References}

1. Lepkowsky CM (2017) Donepezil for constipation in Lewy Body Diseases: Four case studies. Act Nerv Super 59: 19-27. 
Citation: Lepkowsky CM (2017) Donepezil for Lewy Body Constipation: A Six-Month Follow-up. J Mol Genet Med 11: 287. doi: $10.4172 / 1747-0862.1000287$

Page 2 of 2

2. Wakabayashi K, Takahashi H, Takeda S (1989) Lewy Bodies in the enteric nervous system in Parkinson's disease. Arch Histol Cytol 52: 191-194.

3. Braaka H, De Vosb RAI, Bohlc J (2006) Gastric a-synuclein immunoreactive inclusions in Meissner's and Auerbach's plexuses in cases staged for Parkinson's disease-related brain pathology. Neurosci Lett 396: 67-72.

4. Hawkes CH, Del Tredici K, Braak H (2007) Parkinson's disease: a dual-hit hypothesis. Neuropathol Appl Neurobiol 33: 599-614.

5. Minguez-Castellanos A, Chamorro CE, Escamilla-Sevilla F, OrtegaMoreno A, Rebollo AC, et al. (2007) Do a-synuclein aggregates in autonomic plexuses predate Lewy body disorders? Neurology 68: 2012-2018.

6. Holmqvist S, Chutna O, Bousset L, Aldrin-Kirk P, Li W, et al. (2014) Direct evidence of Parkinson pathology spread from the gastrointestinal tract to the brain in rats. Acta Neurol Scand 128: 805-820.

7. Iranzo A, FernándezArcos A, Tolosa E, Serradell M, Molinuevo JL, et al. (2014) Neurodegenerative disorder risk in idiopathic REM sleep behavior disorder: Study in 147 patients. PLoS One 9: e89741.

8. Gjerløff T, Fedorova T, Knudsen K, Munk OL, Nahimi A, et al. (2015) Imaging acetylcholinesterase density in peripheral organs in Parkinson's disease with 11C-donepezil PET. Brain 138: 653-663.

9. Porter AJ, Wattchow DA, Brookes SJH, M Costa (2002) Cholinergic and nitrergic interneurones in the myenteric plexus of the human colon. Gut 51: $70-75$.

10. Jost WH, Schimrigk K (1991) Constipation in Parkinson's disease. Klinische Wochenschrift 69: 906-909.

11. Kaye J, Gage H, Kimber A, Storey L, Trend P (2006) Excess burden of constipation in Parkinson's disease: A pilot study. Mov Disord 21: 1270-1273.

12. Phillips C, Polakoff D, Maue SK, Mauch R (2001) Assessment of Constipation Management in Long-Term Care Patients. J Am Med Dir Assoc 2: 149-154.

13. Kosaka K, Oyanagi S, Matsushita M, Hori A (1976) Presenile dementia with Alzheimer, Pick and Lewy-body changes. Acta Neuropathol 36: 221-233.

14. Perry EK, Smith CJ, Court JA, Perry AH (1990) Cholinergic nicotinic and muscarinic receptors in dementia of Alzheimer, Parkinson and Lewy body types. J Neural 2: 149-158.
15. McKeith IG, Galasko D, Kosaka K, Perry EK, Dickson DW, et al. (1996) Consensus guidelines for the clinical and pathologic diagnosis of dementia with Lewy bodies (DLB): Report of the consortium on DLB international workshop. Neurology 47: 1113-1124.

16. McKeith IG (2000) Spectrum of Parkinson's disease, Parkinson's dementia, and Lewy body dementia. Neurol Clin 18: 865-902.

17. Perez-Lloret S, Barrantes FJ (2016) Deficits in cholinergic neurotransmission and their clinical correlates in Parkinson's disease. Npj Parkinson's Disease 2: 16001.

18. Bosboom JLW, Stoffers D, Wolters EC (2004) Cognitive dysfunction and dementia in Parkinson's disease. J Neural Transm 111: 1303-1315.

19. Birks JS (2006) Cholinesterase inhibitors for Alzheimer's disease. Cochrane Database Systematic Reviews: Dementia and Cognitive Improvement Group 1: CD005593.

20. Minett TSC, Thomas A, Wilkinson LM, Daniel SL, Sanders J, et al. (2003) What happens when donepezil is suddenly withdrawn? An open label trial in dementia with Lewy bodies and Parkinson's disease with dementia. Int J Geriatr Psychiatry 18: 988-993.

21. Mori E, Ikeda M, Kosaka K (2012) Donepezil for dementia with Lewy bodies: A randomized, placebocontrolled trial. Ann Neurol 72: 41-52.

22. Mori E, Ikeda M, Nagai R, Matsuo K, Nakagawa M, et al. (2015) Longterm donepezil use for dementia with Lewy bodies: Results from an open-label extension of Phase III trial. Alzheimers Res Ther 7: 5.

23. Rolinski M, Fox C, Maidment I, Mc Shane R (2012) Cholinesterase inhibitors for dementia with Lewy bodies, Parkinson's disease dementia and cognitive impairment in Parkinson's disease. Cochrane Database Syst Rev 3: CD006504.

24. Jacobsen FM, Comas-Díaz L (1999) Donepezil for psychotropic-induced memory loss. J Clin Psychiatry 60: 698-704.

25. Broad J, Kung VWS, Boundouki G, Aziz Q, De Maeyer JH, et al. (2013) Cholinergic interactions between donepezil and prucalopride in human colon: Potential to treat severe intestinal dysmotility. Br J Pharmacol 170: 1253-1261. 